Quitkin, F. M., Stewart, J. W., McGrath, P. J., et al (1988) Phenelzine versus imipramine in the treatment of probable atypical depressive illness. American Journal of Psychiatry, 145, 306-311.

I. HICKIE

A. WIISON

School of Psychiatry

University of NSW

Mood Disorders Unit

Prince Henry Hospital

Little Bay, Sydney

Australia 2036

\section{Dystonia induced by amphetamine and haloperidol}

SIR: As part of a long-term study of the neuropharmacology of latent inhibition, two healthy volunteers received amphetamine $(5 \mathrm{mg})$ and haloperidol $(5 \mathrm{mg})$. Both developed marked dystonic reactions, such as would be unusual following the administration of haloperidol $(5 \mathrm{mg})$ alone.

The first subject, a 24-year-old woman, $1.7 \mathrm{~m}$ tall and weighing $54 \mathrm{~kg}$, was treated with $5 \mathrm{mg}$ haloperidol and $5 \mathrm{mg}$ dexamphetamine at 10.00 a.m. Twenty-nine hours later she telephoned to report stiffness in her neck. Half an hour later she was examined and found to have increased muscle tone, with neck and limb stiffness and Parkinsonian facies. Her jaw was stiff and her tongue protruded. She had oropharyngeal spasm. She was treated with $10 \mathrm{mg}$ intramuscular procyclidine and the symptoms resolved.

The second subject, a 20-year-old woman, $1.7 \mathrm{~m}$ tall and weighing $63.2 \mathrm{~kg}$, was treated with $5 \mathrm{mg}$ haloperidol and $5 \mathrm{mg}$ dexamphetamine at 10.00 a.m. She telephoned 34 hours later to say that her eyes were rolling upwards. When examined 30 minutes later she was in oculogyric crisis, with acute dystonia of the neck (her head being dorsoflexed against her shoulders) and her back slightly arched - although not in opisthotonos. She was given $10 \mathrm{mg}$ intramuscular procyclidine and her symptoms resolved over 30 minutes.

The pathogenesis of acute dystonia is not fully understood, but Marsden \& Jenner (1980) have argued that it is due to the combined effects of acute dopamine receptor blockade with secondary increase in dopamine turnover followed by a delayed supersensitivity of postsynaptic dopamine $D_{2}$ receptors. Dystonia they argue is caused by the effects of increased dopamine release on supersensitive receptors, as the latter become exposed by drug wash-out. In support of their view, Meldrum et al (1977) have shown that in baboons drug-induced dystonia can be prevented by depleting presynaptic dopamine. In our two healthy volunteers the opposite may have happened, and the combination of amphetamine with haloperidol may have caused marked dystonia by potentiation of dopamine release.

Marsden, C. D. \& JenNer, P. (1980) The pathophysiology of extrapyramidal side effects. Psychological Medicine, 10, 55-72.

Meldrum, B. S., ANlezark, G. M. \& Marsden, C. D. (1977) Acute dystonia as an idiosyncratic response to neuroleptics in baboons. Brain, 100, 313-326.

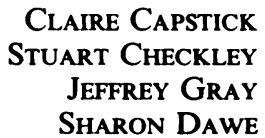

Institute of Psychiatry

London SE5 $8 A F$

\section{Adrenoceptor activity and adenylate cyclase inhibition in depression}

SIR: The human platelet has been extensively used as a model of monoaminergic neurons in the investigation of the amine hypotheses of depression and the effects of antidepressant treatment. Platelet $\alpha_{2}$ adrenergic receptors (AR) are coupled in an inhibitory manner to membrane-bound adenylate cyclase (AC), the effector second messenger system. Platelet $\alpha_{2}$ AR desensitisation has been reported in drugfree depressed patients, expressed as low agonistreceptor affinity or impaired AC inhibition (Siever et al, 1984).

We report the results of two studies which investigated platelet $\alpha_{2} A R$ receptor function and AC inhibition in depressed patients. The first study involved eight patients with DSM-III-R major depression, of mean age 55.4 (s.d. 11.1) years, and 18 normal subjects (hospital personnel) (mean age 49.2 (13.8) years). Blood samples were extracted at 9.00 a.m. for the $\alpha_{2}$ adrenoceptor assay (Doyle et al, 1985). This was done at baseline and at the end of four weeks' treatment with amitriptyline (5 patients) and fluparoxan (an $\alpha_{2}$ adrenoceptor inhibitor) (3 patients). Results were expressed as $K_{d}$ (nm) and $B_{\max }$ ( $\mathrm{fmol} / \mathrm{mg}$ protein). In the second study, eight depressed patients were compared with 11 normal controls (laboratory personnel). Blood samples were extracted at 9.00 a.m. for adenylate cyclase assay (Schultz et al, 1987) at baseline and at weeks 1, 2, 3 and 4 of antidepressant therapy.

The results showed no significant differences in $K_{\mathrm{d}}$ or $B_{\max }$ of $\alpha_{2} \mathrm{AR}$ between depressed patients and normal controls at baseline. At the end of four weeks, the mean value of $K_{d}$ of $\alpha_{2}$ AR was not significantly different between depressed patients and normal controls. $B_{\max }$ of $\alpha_{2}$ AR at the end of treatment, however, was significantly lower in 